\title{
Produtividade de pessegueiros 'Aurora-1' em diferentes espaçamentos e métodos de propagação do porta-enxerto 'Okinawa'
}

\author{
Newton Alex Mayer $\left({ }^{1 *}\right)$; Fernando Mendes Pereira $\left({ }^{2}\right)$ \\ (') Embrapa Clima Temperado, Rodovia BR 392, km 78, Caixa Postal 403, 96010-971 Pelotas (RS), Brasil. \\ (2) Faculdade de Ciências Agrárias e Veterinárias (FCAV), Universidade Estadual Paulista (UNESP), Departamento de Produção \\ Vegetal, Via de Acesso Prof. Paulo Donato Castellane, s/n, 14884-900 Jaboticabal (SP), Brasil. \\ (*) Autor correspondente: alex.mayer@cpact.embrapa.br
}

Recebido: 29/nov./2011; Aceito: 16/jul./2012

Resumo

O presente trabalho teve por objetivo estudar a influência de diferentes espaçamentos entre plantas ( $6 \times 2$ m, 6x3 m e 6x4 m) e de métodos de propagação do porta-enxerto 'Okinawa' (sementes e estacas herbáceas) em variáveis relativas à produção da cultivar Aurora-1 de pessegueiro. O experimento foi desenvolvido em condições de campo, no município de Vista Alegre do Alto (SP), adotando-se as tecnologias recomendadas para a cultura do pessegueiro na região, e as avaliações foram realizadas no segundo e no terceiro ano após o plantio das mudas. Nas condições experimentais adotadas, pode-se concluir que o método de propagação do porta-enxerto 'Okinawa' não interfere em nenhuma das características vegetativas e produtivas da cv. Aurora-1, nas duas safras avaliadas. O espaçamento de $6 \times 2 \mathrm{~m}$ promove significativos aumentos na produtividade do pessegueiro 'Aurora-1'.

Palavras-chave: Prunus persica, adensamento, semente, estaca herbácea.

\section{Productivity of 'Aurora-1' peach trees as affected by spacing and propagation methods of 'Okinawa' rootstock}

\begin{abstract}
The present research had the objective of studying the influence of different spaces in-row ( $6 \times 2 \mathrm{~m}, 6 \times 3 \mathrm{~m}$ and $6 \times 4 \mathrm{~m})$ and propagation methods of 'Okinawa' rootstock (seeds and herbaceous cuttings) in variables related to 'Aurora-1' peach scion production. The trial was carried out at field conditions, in Vista Alegre do Alto, São Paulo State, Brazil, adopting the recommended technologies for peach culture. Evaluations were taken at the $2^{\text {nd }}$ and $3^{\text {rd }}$ years after planting. As conclusions, the propagation methods of 'Okinawa' rootstock did not influence the vegetative and productive characteristics of 'Aurora- 1 ' scion, on both evaluated harvests. The $6 \times 2 \mathrm{~m}$ space promotes significant improvements in 'Aurora-1' peach productivity.
\end{abstract}

Key words: Prunus persica, density, seed, herbaceous cutting.

\section{INTRODUÇÃO}

Nos últimos anos, verifica-se a tendência mundial de elevação dos custos com mão de obra e insumos agrícolas na fruticultura. Esta realidade está conduzindo a fruticultura a sistemas de cultivo que integrem o mínimo de mão de obra, a alta eficiência produtiva e a alta qualidade de frutas, visando ao aumento da produtividade. Um dos fatores que pode contribuir para o aumento da produtividade na fruticultura é o adensamento dos pomares (Dejong et al., 1997; Loreti e Massai, 2006).

A tecnologia de adensamento dos pomares começou a ser popularizada na Europa na década de 1970, especialmente nas culturas de macieira e pereira (Loreti e Massai, 2006). Para o pessegueiro, segundo esses autores, a densidade de plantio pode ser classificada em baixa (400 a 700 plantas ha ${ }^{-1}$ ), média (700 a 1000 plantas ha $\left.{ }^{-1}\right)$ e alta (entre 1000 e 1500 plantas ha ${ }^{-1}$ ). A alta densidade de plantio em pessegueiro já é uma realidade em $100 \%$ dos pomares da Eslovênia, em $60 \%$ dos pomares sul-africanos e em $20 \%$ dos pomares italianos. Estima-se que aproximadamente $10 \%$ das áreas com pessegueiro estejam desenvolvidas sob altas densidades de plantio, cuja expansão ainda depende da disponibilidade de porta-enxertos ananizantes adaptados e de sistemas mais modernos de formação e de condução das plantas (Loreti e MASSAI, 2006).

Os relativos benefícios econômicos da alta densidade de plantio dependem não somente da produção, dos custos de estabelecimento e de manutenção do sistema, 
mas também dos preços pagos pela fruta (Dejong et al., 1997). Em frutíferas de caroço, houve aumentos na densidade de plantio em $57,1 \%$ para o pessegueiro destinado ao mercado in natura, $35,7 \%$ no pessegueiro com fins industriais, $69,0 \%$ nas nectarineiras e $32,1 \%$ na ameixeira, em relação aos indicadores anteriormente adotados, o que pode influenciar diretamente o rendimento das operações de cultivo, os níveis de produtividade e o custo de produção da cultura (CASER et al., 2000). Em regióes de clima tropical ou subtropical, como na mesorregiâo de Ribeirão Preto (SP), Pereira et al. (2002) recomendavam o espaçamento de $6 \times 4 \mathrm{~m}$ ( 416 plantas ha $\left.{ }^{-1}\right)$. Entretanto, com os resultados de pesquisa mais recentes obtidos naquela mesorregião, verificou-se a viabilidade da redução do espaçamento para 6x2 m (Mayer e Pereira, 2008; Mathias et al., 2008), utilizando-se o mesmo manejo de poda (podas de renovação e de frutificação), recomendado para o espaçamento tradicional, com a ressalva de conduzir a planta em formato de taça mais fechada e auxiliando no controle da ferrugem (Araújo et al., 2008).

No Estado do Rio Grande do Sul, os espaçamentos recomendados para o pessegueiro são de três a quatro metros entre as plantas na linha e de seis a sete metros entre as linhas (RASEIRA et al., 1998), o que corresponde a densidades entre 357 e 555 plantas por hectare. Entretanto, com os objetivos de aumentar a produtividade, de obter colheitas significativas já nos primeiros anos, de aumentar a eficiência das pulverizaçóes e de diluir os custos fixos dos pomares, grande parte dos persicultores gaúchos tem utilizado espaçamentos mais reduzidos entre as plantas, tanto em cultivares destinadas ao mercado in natura (região da Serra Gaúcha), como para as do tipo indústria (região de Pelotas, RS), mesmo que ainda não se disponha de porta-enxerto clonal de menor vigor para uso comercial.

Outra tecnologia que pode ser adotada, viável somente em regiôes mais quentes, com cultivares precoces e de ciclo inferior a 100 dias, é a condução dos pomares de pessegueiro em alta ou ultra-altas densidades de plantio sob poda drástica anual ou bienal após a colheita, com até 6666 plantas ha $\mathrm{a}^{-1} \mathrm{em}$ fileiras simples $(3,0 \times 0,5 \mathrm{~m})$ ou 11.428 plantas $_{\text {ha }}{ }^{-1}$, em fileiras duplas $(3,0 \times 0,5 \times 0,5 \mathrm{~m})$ (BARBosa et al., 1999). Entretanto, apesar da viabilidade técnica e econômica, essa tecnologia deixou de ser adotada pelos fruticultores paulistas, principalmente pelo alto investimento na implantação do pomar, pela necessidade de mão de obra diferenciada, pela exigência de maiores conhecimentos técnicos do sistema e também pelo aprendizado tradicional herdado pelos fruticultores, que muitas vezes também limita a adoção de técnicas modernas.

Outro aspecto ligado ao adensamento dos pomares é a necessidade da preservação da identidade genética para homogeneizar o vigor do porta-enxerto entre as plantas. Constata-se, entretanto, que poucas são as comprovaçóes científicas sobre a viabilidade técnica do uso de porta-enxertos para pessegueiro propagados vegetativamente, no
Brasil. Viveiristas e fruticultores propagam porta-enxertos exclusivamente por sementes, sendo o 'Okinawa' o mais utilizado na Regiấo Sudeste, e caroços sem identificaçấo varietal, obtidos nas indústrias de conservas, o material comumente utilizado na Região Sul (Pereira e Mayer, 2005).

Considerando-se a tendência do aumento da densidade de plantio em pessegueiro e a necessidade de estudos de campo sobre a viabilidade técnica do uso de porta-enxertos propagados vegetativamente, idealizou-se o presente trabalho que teve por objetivo estudar a frutificação, a produçáo e a produtividade de pessegueiros 'Aurora-1' em diferentes espaçamentos e métodos de propagaçáo do porta-enxerto 'Okinawa'. Formulou-se a hipótese de que diferentes espaçamentos entre plantas e métodos de propagação do porta-enxerto 'Okinawa' podem influenciar características físicas de frutos, a produção e a produtividade da copa 'Aurora-1'.

\section{MATERIAL E MÉTODOS}

Foram produzidas mudas de pessegueiro [Prunus persica (L.) Batsch] cv. Aurora-1, enxertadas pelo método de borbulhia em escudo modificada (Pereira e Mayer, 2005). O porta-enxerto utilizado foi a cv. Okinawa [Prunus persica (L.) Batsch], propagado por dois métodos: enraizamento de estacas herbáceas em câmara de nebulização intermitente, com o uso de $2000 \mathrm{mg} \mathrm{L}^{-1}$ de ácido indolbutírico (Nachtigal e Pereira, 2000) ou por germinação de sementes estratificadas em geladeira (Pereira e MAYER, 2005). Todos os porta-enxertos foram mantidos em sacos plásticos perfurados $(28 \mathrm{x} 18 \mathrm{~cm})$, contendo substrato comercial (Rendmax Citrus ${ }^{\circ}$ ), em viveiro com piso cimentado e coberto com tela de sombreamento de $50 \%$.

$\mathrm{O}$ experimento foi instalado em condiçóes de campo, na Fazenda Santa Alzira, Município de Vista Alegre do Alto (SP), em Argissolo Vermelho-Amarelo eutrófico de textura arenosa média (EMBRAPA, 2006). O preparo do solo foi realizado conforme as recomendaçóes técnicas para o cultivo do pessegueiro na região (Pereira et al., 2002) e as covas $(50 \times 50 \times 50 \mathrm{~cm})$ foram preparadas de acordo com o espaçamento de cada parcela $(6 \times 2 \mathrm{~m}$, $6 \times 3 \mathrm{~m}$ ou $6 \times 4 \mathrm{~m}$ ). Em cada cova foram aplicados: $20 \mathrm{~kg}$ de esterco curtido de bovinos, 1 a $1,5 \mathrm{~kg}$ de superfosfato simples e $60 \mathrm{~g}$ de $\mathrm{K}_{2} \mathrm{O}$ (Pereira et al., 2002), aos 30 dias antes do transplantio das mudas. Transcorrido este período, as mudas foram transplantadas em agosto de 2003, mantendo-se o torrão intacto. Em seguida, o ramo principal de cada muda foi podado a $50 \mathrm{~cm}$ de altura, objetivando forçar a brotação de ramos laterais.

Foram realizados todos os tratos culturais recomendados para a cultura do pessegueiro na microrregião de Jaboticabal (SP), inclusive com a poda de renovação após a colheita e irrigação por microaspersão (Pereira et al., 2002). No período de avaliação, as podas de frutificação 
foram realizadas entre os dias 11 e 13 de julho de 2005 e 30 de junho e $1 .^{\circ}$ de julho de 2006, aplicando-se, em seguida, a cianamida hidrogenada na dose de $0,29 \%$ de i.a. (Dormex a 0,6\%) (Pereira et al., 2002).

No segundo e no terceiro anos após o transplantio (2005 e 2006, respectivamente), foram realizadas as avaliaçóes conforme descrição a seguir. Para as primeiras cinco variáveis, foi eleita em uma única planta representativa da área útil parcela, desprezando-se as duas plantas periféricas; para as demais variáveis, foram utilizadas todas as plantas da parcela.

- Número de ramos por planta (NR): variável determinada após a poda de frutificaçáo, em 24 de agosto de 2005 (42 dias após a aplicação da cianamida hidrogenada) e 26 de julho de 2006 (23 dias após a aplicação da cianamida hidrogenada). Para tanto, foram considerados os ramos mistos (contendo gemas vegetativas e floríferas) com, pelo menos, $10 \mathrm{~cm}$ de comprimento.

- Número de frutos por ramo misto antes do raleio (NFRA): em 28 de setembro de 2005 (35 dias após o final da floração) e 25 de setembro de 2006 (45 dias após o final da floração), os frutinhos estavam com diâmetro adequado para a realização do raleio (em torno de $20 \mathrm{~mm}$ ). Nas plantas marcadas, foram etiquetados 20 ramos mistos representativos, localizados no terço mediano da planta, sendo cinco ramos em cada quadrante. Antes da realização do raleio, procedeu-se a contagem do número de frutos por ramo misto marcado, considerando-se apenas aqueles com desenvolvimento normal.

- Número de frutos por ramo misto depois do raleio (NFRD): nos mesmos dias das avaliaçôes da variável NFRA, foi realizado o raleio manual nos ramos etiquetados, quando necessário (Pereira et al., 2002), deixando-se, no máximo, quatro frutos por ramo (nos casos de ramos adequadamente desenvolvidos e com mais de $40 \mathrm{~cm}$ de comprimento). Procedeu-se, em seguida, à contagem do número de frutos remanescentes por ramo marcado. Em funçáo da baixa frutificação, ocorrida em 2006, o raleio de frutos não foi necessário.

- Número de brotos por ramo misto (NB): variável avaliada nos mesmos dias das variáveis NFRA e NFRD, portanto, no momento do raleio. Foram utilizados os mesmos 20 ramos etiquetados por parcela e consideraram-se brotos aqueles com, pelo menos, três folhas.

- Número de frutos por planta (NFP): em 11 de outubro de 2005 (48 dias após o final do período da floração) e 27 de setembro de 2006 (47 dias após o fim do período da floração), foram realizadas as contagens do número de frutos total por planta, utilizando-se as mesmas plantas representativas de cada parcela.

Objetivando-se amostrar frutos mais uniformes e representativos das parcelas, procederam-se amostragens em duas colheitas em 2005 ( 28 de outubro e 3 de novembro) e em 17 de outubro de 2006, datas mais próxima da metade do período de colheita. Foram colhidos, ao acaso, 20 frutos por parcela, em estádio "de vez". Em laboratório, foram mensuradas as seguintes variáveis:
- Diâmetro transversal do fruto (DT): o diâmetro na região equatorial do fruto foi mensurado com paquímetro digital, na linha de sutura, e expresso em $\mathrm{mm}$, com duas casas decimais.

- Diâmetro longitudinal do fruto (DL): foi obtida a maior dimensão da altura do fruto, com auxílio de paquímetro digital, e expresso em $\mathrm{mm}$, com duas casas decimais.

- Massa do fruto (MF): individualmente, obteve-se o valor da massa de cada fruto, em balança eletrônica digital, com duas casas decimais, e os valores foram expressos em $\mathrm{g}$.

- Produção por planta (PPl): foi estimada multiplicando-se o número de frutos por planta pela massa média do fruto (em kg), e os dados foram expressos em $\mathrm{kg} \mathrm{pl}^{-1}$.

- Produtividade por hectare (PHa): foi estimada multiplicando-se a produção por planta (em kg) pelo número de plantas por hectare de cada espaçamento (833 plantas por hectare, no espaçamento $6 \times 2 \mathrm{~m} ; 555$ plantas por hectare, no espaçamento $6 \times 3 \mathrm{~m}$; e 416 plantas por hectare, no espaçamento $6 \times 4 \mathrm{~m}$ ), dividindo-se por 1000 , sendo os dados expressos em $t$ ha $^{-1}$.

O experimento foi instalado segundo delineamento experimental de blocos ao acaso, com quatro repetições, esquema fatorial $2 \times 3$ (métodos de propagação do porta-enxerto $\mathrm{x}$ espaçamentos entre plantas), totalizando 24 parcelas. Os níveis do fator método de propagaçáo foram semente e estaca herbácea e os níveis do espaçamento entre plantas: $6 \times 2 \mathrm{~m}, 6 \times 3 \mathrm{~m}$ e $6 \times 4 \mathrm{~m}$. Cada parcela foi constituída por 6, 4 e 3 plantas, respectivamente, para cada espaçamento testado, de modo que cada parcela ocupasse uma área de $72 \mathrm{~m}^{2}$, totalizando $1728 \mathrm{~m}^{2}$ de área experimental. Os dados foram submetidos à análise de variância, pelo teste $\mathrm{F}$, e as médias comparadas pelo teste de Tukey, ao nível de 5\%.

\section{RESULTADOS E DISCUSSÃO}

Nenhuma das variáveis estudadas (Tabelas 1 e 2) foi influenciada significativamente pelos métodos de propagação do porta - enxerto 'Okinawa', em ambos os anos de avaliaçôes (2005 e 2006). Esses resultados comprovam, em condiçôes de campo, a viabilidade técnica do uso do 'Okinawa' propagado por estacas herbáceas. Mayer e Pereira (2008) também comprovaram a inexistência de inconvenientes do uso de 'Okinawa' propagado vegetativamente como porta-enxerto de 'Aurora-1', não se observando diferenças significativas no diâmetro do tronco, na fenologia e na produção de gemas floríferas e vegetativas, em relação às plantas enxertadas em 'Okinawa' propagado por sementes.

$\mathrm{O}$ rápido crescimento e desenvolvimento dos pessegueiros podem ser comprovados com o elevado número de ramos mistos deixados por planta após a poda de frutificação (em torno de 180 e 300 ramos por planta, respectivamente, no segundo e terceiro ano após o transplantio), que propiciaram precocidade na produção (Tabela 2). Em 
2005, devido às condiçóes climáticas normais na regiăo (Volpe, 2007), houve a necessidade de raleio de aproximadamente $37 \%$ dos frutos, em ambos os métodos de propagação do porta-enxerto 'Okinawa' estudados. Entretanto, em 2006, as condiçôes climáticas foram desfavoráveis, dispensando essa operação (Tabela 1). A precocidade da produção, comprovada com a obtenção de mais de 260 frutos por planta em 2005 (Tabela 1), proporcionou produçáo de 19,23 e 22,27 kg planta-1 nas plantas enxertadas em 'Okinawa' propagadas, respectivamente, por semente e estaca herbácea (Tabela 2).

Um aspecto que normalmente é questionado, tanto no meio científico como no produtivo, refere-se à ancoragem das plantas propagadas vegetativamente e ao comportamento em períodos de estiagem, em função da inexistência de uma raiz pivotante típica. A literatura reporta que, em pessegueiros 'Aurora-1' com 34 meses de idade, o método de propagação do porta-enxerto 'Okinawa' (sementes ou estacas herbáceas) não influenciou as massas fresca e seca de raízes e que ambos os métodos de propagação proporcionaram semelhante distribuição das raízes finas $(\varnothing<2,8 \mathrm{~mm})$ e grossas $(\varnothing \geq 2,8 \mathrm{~mm})$ ao redor da planta. O crescimento de raízes grossas foi além de $0,4 \mathrm{~m}$ de profundidade, permitindo às plantas ancoragem adequada, em ambos os métodos de propagação estudados (MAYer et al., 2007).

Os efeitos do método de propagação (sementes e estacas lenhosas) dos porta-enxertos 'Guardian seleção SC317-7' e 'Lovell' na cultivar-copa 'Cresthaven' de pessegueiro foram estudados por BeCKMAN et al. (2006), entre o quarto e o sexto ano de produçáo, no espaçamento de $6,1 \times 1,8 \mathrm{~m}$. Os autores concluíram que não existem vantagens ou desvantagens horticulturais entre o 'Guardian' propagado por sementes e por estacas lenhosas, pois ambos os métodos de propagação proporcionaram similar vigor (área da seção do tronco), produçáo $\left(\mathrm{kg} \mathrm{pl}^{-1}\right)$, eficiência produtiva $\left(\mathrm{kg} \mathrm{cm}^{-2}\right)$ e peso médio de fruto $(\mathrm{g})$. Entre os dois métodos de propagaçáo do 'Lovell', o comportamento também foi similar, exceção apenas para a eficiência produtiva no sexto ano e na produçáo acumulada dos três anos avaliados, que foi maior quando propagado por sementes. Os autores mencionam uma pequena vantagem

Tabela 1. Efeito do método de propagação do porta-enxerto 'Okinawa' e do espaçamento entre plantas de pessegueiro 'Aurora-1' no número de ramos por planta (NR), número de frutos por ramo misto antes (NFRA) e depois do raleio (NFRD), número de brotos por ramo misto (NB) e número de frutos por planta (NFP), no segundo (2005) e no terceiro ano (2006) após o transplantio. Vista Alegre do Alto, SP, 2006

\begin{tabular}{|c|c|c|c|c|c|c|c|c|c|c|}
\hline \multirow{2}{*}{$\begin{array}{l}\text { Método } \\
\text { propagação }\end{array}$} & \multicolumn{2}{|c|}{ NR } & \multicolumn{2}{|c|}{ NFRA } & \multicolumn{2}{|c|}{ NFRD } & \multicolumn{2}{|c|}{ NB } & \multicolumn{2}{|c|}{ NFP } \\
\hline & 2005 & 2006 & 2005 & 2006 & 2005 & 2006 & 2005 & 2006 & 2005 & 2006 \\
\hline Semente & $178,25 \mathrm{a}$ & $289,50 \mathrm{a}$ & $2,62 \mathrm{a}$ & $0,43 a$ & $1,65 a$ & $0,43 a$ & $3,78 \mathrm{a}$ & $2,30 \mathrm{a}$ & $263,67 a$ & $89,75 a$ \\
\hline Estaca herbácea & $184,58 \mathrm{a}$ & $307,25 \mathrm{a}$ & $2,75 \mathrm{a}$ & $0,33 \mathrm{a}$ & $1,74 \mathrm{a}$ & $0,33 a$ & $3,53 \mathrm{a}$ & $2,12 \mathrm{a}$ & $296,42 \mathrm{a}$ & $100,08 \mathrm{a}$ \\
\hline $\mathrm{F}_{\text {método }}$ & 0,05 ns & 0,85 ns & 0,20 ns & $1,16^{\mathrm{ns}}$ & 0,77 ns & $1,16^{\mathrm{ns}}$ & $0,93^{\text {ns }}$ & 0,67 ns & 1,51 ns & $0,75^{\mathrm{ns}}$ \\
\hline \multicolumn{11}{|l|}{ Espaçamento } \\
\hline $6 \times 2 \mathrm{~m}$ & $172,75 \mathrm{a}$ & $308,13 a$ & $2,68 \mathrm{a}$ & $0,63 \mathrm{a}$ & $1,81 \mathrm{a}$ & $0,63 a$ & $3,34 a$ & $3,54 \mathrm{a}$ & $277,13 \mathrm{a}$ & $137,38 \mathrm{a}$ \\
\hline $6 \times 3 \mathrm{~m}$ & $150,00 \mathrm{a}$ & $305,75 a$ & $2,67 \mathrm{a}$ & $0,30 \mathrm{~b}$ & $1,65 \mathrm{a}$ & $0,30 \mathrm{~b}$ & $4,01 \mathrm{a}$ & $1,65 \mathrm{~b}$ & $279,25 \mathrm{a}$ & $90,63 \mathrm{~b}$ \\
\hline $6 \times 4 m$ & $221,50 \mathrm{a}$ & $281,25 \mathrm{a}$ & $2,72 \mathrm{a}$ & $0,22 b$ & $1,64 \mathrm{a}$ & $0,22 b$ & $3,61 \mathrm{a}$ & $1,46 \mathrm{~b}$ & $283,75 \mathrm{a}$ & $56,75 b$ \\
\hline & 2,34 ns & 0,80 ns & 0,01 ns & 6,42 ** & $1,16^{\mathrm{ns}}$ & 6,42 ** & $2,42^{n s}$ & 36,99 ** & 0,02 ns & 15,28 ** \\
\hline & $0,43^{\text {ns }}$ & $0,09^{n s}$ & 1,00 ns & $0,05^{\text {ns }}$ & $1,75^{\text {ns }}$ & $0,05^{\text {ns }}$ & 0,99 ns & $0,11^{\text {ns }}$ & 0,01 ns & $1,17^{\mathrm{ns}}$ \\
\hline $\mathrm{F}_{\text {blocos }}$ & $0,50^{\text {ns }}$ & 2,99 ns & 3,72 * & 2,69 ns & 3,63 * & 2,69 ns & $2,23^{\mathrm{ns}}$ & 3,17 ns & 0,12 ns & $1,97 \mathrm{~ns}$ \\
\hline CV (\%) & 37,22 & 15,82 & 25,94 & 63,64 & 14,90 & 63,64 & 16,81 & 24,21 & 23,28 & 30,86 \\
\hline
\end{tabular}

Médias seguidas por letras distintas, na mesma coluna, diferem entre si pelo teste de Tukey. ${ }^{*}$ significativo a $5 \%$; ${ }^{* *} 1 \%$ de probabilidade; ${ }^{\text {ns }}$ não significativo.

Tabela 2. Efeito do método de propagação do porta-enxerto 'Okinawa' e do espaçamento entre plantas de pessegueiro 'Aurora-1' no diâmetro transversal (DT, em mm), diâmetro longitudinal (DL, em mm) e massa do fruto (MF, em g), produção por planta ( $\mathrm{PPl}$, em $\mathrm{kg}^{-1} \mathrm{pl}^{-1}$ e produtividade por hectare (PHa, em t ha ${ }^{-1}$ ), no segundo (2005) e no terceiro ano (2006) após o transplantio. Vista Alegre do Alto, SP, 2006

\begin{tabular}{|c|c|c|c|c|c|c|c|c|c|c|}
\hline \multirow{2}{*}{$\begin{array}{l}\text { Método } \\
\text { Propagação }\end{array}$} & \multicolumn{2}{|c|}{ DT } & \multicolumn{2}{|c|}{ DL } & \multicolumn{2}{|c|}{ MF } & \multicolumn{2}{|c|}{ PPI } & \multicolumn{2}{|c|}{$\mathrm{PHa}$} \\
\hline & 2005 & 2006 & 2005 & 2006 & 2005 & 2006 & 2005 & 2006 & 2005 & 2006 \\
\hline Semente & $51,83 \mathrm{a}$ & $57,05 \mathrm{a}$ & $63,71 \mathrm{a}$ & $69,25 \mathrm{a}$ & $73,26 \mathrm{a}$ & $108,28 \mathrm{a}$ & $19,23 \mathrm{a}$ & $10,13 \mathrm{a}$ & $11,61 \mathrm{a}$ & $6,80 \mathrm{a}$ \\
\hline Estaca herbácea & $51,97 \mathrm{a}$ & $57,33 \mathrm{a}$ & $64,02 \mathrm{a}$ & $69,69 \mathrm{a}$ & $74,87 \mathrm{a}$ & $112,10 \mathrm{a}$ & $22,27 \mathrm{a}$ & $11,41 \mathrm{a}$ & $13,53 \mathrm{a}$ & $7,63 \mathrm{a}$ \\
\hline $\mathrm{F}_{\text {método }}$ & $0,06^{\mathrm{ns}}$ & 0,09 ns & 0,24 ns & $0,11^{\text {ns }}$ & 0,59 ns & $0,52^{\text {ns }}$ & 2,23 ns & $0,72^{\text {ns }}$ & 2,97 ns & 0,69 ns \\
\hline \multicolumn{11}{|l|}{ Espaçamento } \\
\hline $6 \times 2 \mathrm{~m}$ & $52,82 \mathrm{a}$ & $58,50 \mathrm{a}$ & $64,93 \mathrm{a}$ & $71,97 \mathrm{a}$ & $76,83 \mathrm{a}$ & $117,76 \mathrm{a}$ & $21,37 \mathrm{a}$ & $16,34 \mathrm{a}$ & $17,80 \mathrm{a}$ & $13,61 \mathrm{a}$ \\
\hline $6 \times 3 \mathrm{~m}$ & $51,63 a$ & $56,89 a$ & $64,12 a b$ & $68,40 \mathrm{a}$ & $74,81 \mathrm{a}$ & $108,10 a$ & 20,97 a & $10,01 \mathrm{~b}$ & $11,64 b$ & $5,56 \mathrm{~b}$ \\
\hline $6 \times 4 \mathrm{~m}$ & $51,25 \mathrm{a}$ & $56,17 \mathrm{a}$ & $62,55 \mathrm{~b}$ & $68,04 \mathrm{a}$ & $70,56 \mathrm{a}$ & $104,72 \mathrm{a}$ & $19,92 \mathrm{a}$ & $5,96 \mathrm{~b}$ & $8,28 \mathrm{~b}$ & $2,48 b$ \\
\hline $\mathrm{F}_{\text {espaçamento }}$ & $3,01^{\text {ns }}$ & $2,21^{\mathrm{ns}}$ & 5,03 * & 3,54 ns & $3,10^{\mathrm{ns}}$ & $2,19^{\text {ns }}$ & $0,18^{\text {ns }}$ & $15,88^{* *}$ & $24,99 * *$ & 44,46 ** \\
\hline $\mathrm{F}_{\text {método x esp. }}$ & 0,07 ns & 0,59 ns & $0,23^{\mathrm{ns}}$ & 0,66 ns & 0,40 ns & $0,39^{\text {ns }}$ & 0,08 ns & 0,82 ns & 0,42 ns & 0,52 ns \\
\hline $\mathrm{F}_{\text {blocos }}$ & $1,34^{\text {ns }}$ & $1,51^{\mathrm{ns}}$ & $1,58^{\mathrm{ns}}$ & $1,19^{\text {ns }}$ & $1,34^{\mathrm{ns}}$ & $2,54^{\mathrm{ns}}$ & $0,36^{\text {ns }}$ & $2,53^{\mathrm{ns}}$ & $0,62^{\text {ns }}$ & $2,911^{\mathrm{ns}}$ \\
\hline CV (\%) & 2,57 & 3,97 & 2,39 & 4,70 & 6,95 & 11,74 & 24,02 & 34,45 & 21,73 & 33,79 \\
\hline
\end{tabular}

Médias seguidas por letras distintas, na mesma coluna, diferem entre si pelo teste de Tukey. ${ }^{*}$ significativo a $5 \%$; ${ }^{* *} 1 \%$ de probabilidade; ${ }^{\text {ns }}$ năo significativo. 
da propagação por estacas lenhosas em relação às sementes, devido à menor produção de ramos ladrôes, em ambas as cultivares de porta-enxertos.

$\mathrm{O}$ menor espaçamento testado $(6 \times 2 \mathrm{~m})$ propiciou aumento na frutificação, na brotação, no número de frutos por planta e na produção por planta em 2006, ano em que a umidade relativa do ar, o número de dias com chuva e a precipitação pluvial ficaram abaixo da média histórica. Também se verificou que, nesse ano, a insolação e a temperatura máxima do ar foram acima da média histórica da região (Volpe, 2007), ou seja, a redução do espaçamento entre as plantas na linha e sua condução em forma de taça mais fechada minimizou os efeitos adversos do clima, favorecendo a frutificaçáo. Segundo Mathias et al. (2008), os espaçamentos de 6x4 m, 6x3 m e $6 \times 2 \mathrm{~m}$ não exerceram efeito significativo na coloração externa, no ângulo de cor e na luminosidade do mesocarpo, na firmeza e na acidez de pêssegos 'Aurora-1'. Entretanto, o espaçamento de $6 \times 4 \mathrm{~m}$ induziu a produçáo de pêssegos menores e mais leves, mas com maior teor de sólidos solúveis e maior relação SS/AT.

No presente trabalho, destaca-se que o principal efeito dos diferentes espaçamentos estudados ocorreu na produtividade (Tabela 2). O espaçamento de $6 \times 2 \mathrm{~m}$ propiciou aumentos de 2,1 (2005) e de 5,5 vezes (2006) na produtividade, comparativamente ao espaçamento tradicional de 6x4 m, recomendado na mesorregião de Ribeirão Preto (Pereira et al., 2002), ou seja, em 2005, o ganho obtido foi de 9,52 $\mathrm{t} \mathrm{ha}^{-1} \mathrm{e}$, em 2006, o ganho foi de 11,13 $\mathrm{t} \mathrm{ha}^{-1}$, comparando-se o espaçamento de $6 \times 2 \mathrm{~m}$ com o espaçamento de $6 \times 4 \mathrm{~m}$. Nessa mesorregião, a oferta de pêssegos é muito baixa entre a segunda quinzena de agosto e a primeira quinzena de outubro, o que torna os preços altamente compensadores, podendo atingir valores médios de R\$ 2,00 o quilo (Pereira et al., 2002). De acordo com os ganhos de produtividade obtidos no presente estudo, constata-se a possibilidade de aumentar a receita bruta em até $\mathrm{R} \$ 20.000,00$ por hectare, utilizando o espaçamento de $2 \mathrm{~m}$ entre as plantas na linha.

\section{CONCLUSÃO}

Pode-se concluir que o método de propagação do porta-enxerto 'Okinawa' náo interfere em nenhuma das características vegetativas e produtivas da cv. Aurora-1, nas duas safras avaliadas. O espaçamento de $6 \times 2 \mathrm{~m}$ promove significativos aumentos na produtividade do pessegueiro 'Aurora-1'.

\section{AGRADECIMENTOS}

Os autores agradecem à FAPESP pelo apoio financeiro (Processos n. ${ }^{\text {os }} 04 / 12110-6$ e 05/50157-7).

\section{REFERÊNCIAS}

ARAÚJO, J.P.C.; RODRIGUES, A.; SCARPARE FILHO, J.A.; $\mathrm{PIO}, \mathrm{R}$. influência da poda de renovaçáo e controle da ferrugem nas reservas de carboidratos e produçáo de pessegueiro precoce. Revista Brasileira de Fruticultura, v.30, p.331-335, 2008.

BARBOSA, W.; CAMPO DALL'ORTO, F.A.; OJIMA, M.; SANTOS, R.R.; KALIL, G.P.C.; FAHL, J.I.; CARELLI, M.L.C. O pessegueiro em pomar compacto. IX. Dez anos de produçáo de cultivares sob poda drástica bienal. Pesquisa Agropecuária Brasileira, v.34, p.69-76, 1999.

BECKMAN, T.G.; NYCZEPIR, A.P.; MYERS, S.C. Performance of peach rootstocks propagated as seedlings vs. cuttings. Acta Horticulturae, n.713, p.289-293, 2006.

CASER, D.V.; CAMARGO, A.M.M.P.; AMARO, A.A. Densidades de plantio em culturas perenes na agricultura paulista. Informaçóes Econômicas, v.30, p.45-53, 2000.

DEJONG, T.M.; TSUJI, W.; DOYLE, J.F.; GROSSMAN, Y.L. Do high density systems really pay? Evaluation of high density systems for cling peaches. Acta Horticulturae, n.451, p.599-604, 1997.

EMBRAPA. Centro Nacional de Pesquisa de Solos (Rio de Janeiro, RJ). Sistema brasileiro de classificação de solos. 2. ed. Rio de Janeiro: EMBRAPA-SPI, 2006. 306p.

LORETI, F.; MASSAI, R. State of the art on peach rootstocks and orchard systems. Acta Horticulturae, n.713, p.253-268, 2006.

MATHIAS, C.; MAYER, N.A.; MATTIUZ, B.; PEREIRA, F.M. Efeito de porta-enxertos e espaçamentos entre plantas na qualidade de pêssegos 'Aurora-1'. Revista Brasileira de Fruticultura, v.30, p.165-170, 2008.

MAYER, N.A.; PEREIRA, F.M.; BARBOSA, J.C.; KOBA, V.Y. Distribuiçáo do sistema radicular o pessegueiro 'Okinawa' propagado por sementes e por estacas herbáceas. Revista Brasileira de Fruticultura, v.29, p.699-704, 2007.

MAYER, N.A.; PEREIRA, F.M. Métodos de propagação do portaenxerto 'Okinawa' e espaçamentos: efeitos no diâmetro do tronco, fenologia e produção de gemas em pessegueiros 'Aurora-1'. Revista Brasileira de Fruticultura, v.30, p.560-565, 2008.

NACHTIGAL, J.C.; PEREIRA, F.M. Propagação do pessegueiro (Prunus persica (L.) Batsch) cultivar Okinawa por meio de estacas herbáceas em câmara de nebulização. Revista Brasileira de Fruticultura, v.22, p.208-212, 2000.

PEREIRA, F.M.; NACHTIGAL, J.C.; ROBERTO, S.R. Tecnologia para a cultura do pessegueiro em regióes tropicais $\mathrm{e}$ subtropicais. Jaboticabal: Funep, 2002. 62p.

PEREIRA, F.M.; MAYER, N.A. Pessegueiro: tecnologias para a produção de mudas. Jaboticabal: Funep, 2005. 65p.

RASEIRA, A.; PEREIRA, J.F.M.; MEDEIROS, A.R.M.; CARVALHO, F.L.C. Instalaçáo e manejo do pomar. In: MEDEIROS, C.A.B.; RASEIRA, M.C.B. A cultura do pessegueiro. Brasília: Embrapa SPI; Pelotas: Embrapa CPCAT, 1998. p.130-160.

VOLPE, C.A. Estação Agroclimatológica. 2007. Disponível em: $<$ http//www.exatas.fcav.unesp.br/estacao > Acesso em: 13/2/2007. 